\title{
ESTUDIOS
}

\section{Formas del Fausto}

Gobre el Fausto (1866) de Estanislao del Campo (Argentina, 18341880 ) ya se ha dicho casi todo: sus fuentes, la génesis de su composición, el cotcjo con el libreto de la ópera, sus peculiaridades lingüisticas, su métrica y las variantes entre el manuscrito y las ediciones sucesivas, sus referencias a la realidad social, ctnográfica y política de la Argentina, el lugar que ocupa en la bio-bibliografía del autor, su significación dentro de la llamada literatura gauchesca, la fortuna que ha tenido entre los críticos, sus valores estéticos, etc. Por mi parte trataré de añadir, a ese saber, un diseño de las formas del Fausto. Me refiero especialmente a sus "formas interiores", menos visibles y, por lo tanto, menos estudiadas. Es posible que esas formas no siempre fueran intencionales; hasta es posible que, de mostrárselas alguien, Del Campo las hubiera negado. Están en el texto, pero para verlas hay que radiografiarlo después de inyectarle ciertas sustancias que tiñan diversamente sus sistemas de nervios, arterias, tejidos y órganos. Confieso que, en algunos casos, dudo de que esta radiografía sea objetiva. Después de todo, mi diseño también "è cosa mentale". Diseñaré cinco formas: la forma humorística que resulta al invertir un tópico serio, la forma perturbadora que resulta al desdoblar una situación humana, la forma ambigua que resulta al reduplicar el fingimiento de la credulidad, la forma menguante que resulta al imitar una imitación y la forma contrapuntística que resulta al combinar dos estilos.

I. INVERSIÓN DEL TóPICO DEL "THEATRUM MUNDI"

La comparación del mundo con un teatro y del hombre con un actor ya estaba en Platón, pasó a los estoicos (Epicteto, Séneca), la usaron los 
cristianos (de San Pablo a San Agustín; de Juan Crisóstomo a Juan de Salisbury), la difundieron los autores del Renacimiento (Shakespeare, Lope de Vega, Rotrou) y quedó sistematizada en el barroco auto sacramental de Calderón: El Gran Teatro del Mundo. ${ }^{1}$ Tan conocida era en el siglo XvII que, cuando Don Quijote quiso explicarla, Sancho, nada menos que el ignorante Sancho, exclamó: "Brava comparación, aunque no tan nueva que yo no lo haya oido muchas y diversas veces" (II,12). Consciente, pues, de que esa metáfora se estaba desgastando, Cervantes la puso al revés - no ya la vida como teatro, sino el teatro como vida- y salió con la aventura del espectador Don Quijote que toma en serio el espectáculo del retablo de Maese Pedro (II, 26). Ya en el Quijote apócrifo Don Quijote había interrumpido a mano armada la representación de una comedia de Lope de Vega por creer que a la reina se la vejaba de verdad (XXVIII); pero el autor de ese Quijote, quien quiera que fuese, no supo lo que hacía; Cervantes es, pues, el primero que, en nuestra lengua, invierte la fórmula con plena conciencia. Fórmula que, así invertida, ha producido siempre felices efectos humorísticos. En vez de mostrarnos el mundo como un teatro contemplado por un lúcido Dios - que había sido la idea de filósofos paganos y predicadores cristianos - nos mostrará el teatro como un mundo contemplado por un hombre ofuscado. Y la comicidad dependerá del tipo de ofuscación que padezca este hombre que confunde la ficción escénica con la realidad misma.

No se ha estudiado todavía la historia de la inversión del "mundo como teatro" en "teatro como mundo". Daré unos pocos ejemplos.

Henry Fielding, Tom Jones (1749), XvI, 5: Tom Jones se divierte con los comentarios de Partridge -un Sancho Panza inglés- durante la representación de Hamlet. Aunque Partridge sabe que lo que está viendo es un drama, se asusta de todos modos porque cree que el diablo se ha metido en el escenario y las emociones de los actores son reales.

Fernán Caballero, La Gaviota (1849), xvi: el campesino Momo cuenta a su madre y a su abuela la ópera Otiello, de Rossini, que oyó en Madrid; cree que a María - que cantaba en el papel de Desdémona- la han matado de verdad.

Serafí Pitarra [Frederic Soler], Faust. Ressenya de la ópera que ab dit titol's representá ab estraordinari aplauso en lo Gran Teatro del Liceo escrit en vers $y$ en catalá del que ara's parla (1864): un hombre del pue-

1 Ernst Robert Curtius, "Metáforas del teatro", Literatura europea y Edad Niedia latina (México, 1955), I, 203-211. Antonio Vilanova, "El tema del Gran teatro del Mundo", Boletin de la Real Academia de Buenas Letras de Barcelona, XXIII (1950), 153-188. Jean Jacquot, "Le Thèátre du Monde de Shakespeare à Calderón", Revue de Litterature Comparée XXXI, 3 (1957), 341-372. 
blo asiste al estreno del Fausto de Gounod, en versión italiana, y tergiversa las escenas de acuerdo a su propia imaginación y a sus experiencias locales.

No creo que Estanislao del Campo se haya inspirado en ninguna de estas obras para imaginar su Fcusto. ${ }^{2}$ La situación del rústico en la metrópoli estaba en el aire, y Del Campo no necesitaba salir del Río de la Plata para conocerla: la tenía a mano. Bartolomé Hidalgo la había tocado en su "Relación": el gaucho Contreras va a la ciudad de Buenos Aires para las fiestas mayas de 1822 y se mete en un teatro, sólo que no alcanza a ver la comedia porque estalla un incendio. Del Campo llenará ese hueco de la función no vista con un gaucho que sí la ve. Primero lo intentó en la "Carta de Anastasio el Pollo sobre el beneficio de la señora La Gruya", de 1857, donde el paisano contaba sus impresiones de la ópera Saffo, de Giovanni Paccini, sin advertir que era pura ficción; casi diez años después lo logró —admirablemente- con el Fausto. ${ }^{3}$

Del Campo delegó su punto de vista en un narrador que, en habla campesina, refiere el encuentro del paisano Laguna con Anastasio el Pollo. En el curso del diálogo, el Pollo cuenta a Laguna, punto por punto, desde que entró hasta que cayó el telón final, lo que vio en el Teatro Colón; o sea, la versión italiana de la ópera Fausto de Gounod. La historia de Fausto, Margarita y Mefistófeles aparece recreada por las impresiones de los amigos.

\section{DESDOBLAMIENTO INTERIOR}

El poema fue el relato de un relato. En cierto sentido fue un espectáculo dentro de un espectáculo, porque la progresión dramática con que

2 Rubén Benítez sí sugiere que Del Campo se inspiró en La Gaviota: "Una posible fuente española del Fausto de Estanislao del Campo", Revista Iberoamericana, XXXI, 60 (1965), 151-171, pero las semejanzas que señala eno serán mieras coincidencias, explicables porque se desprenden de una situación común: el rústico en un teatro urbano? Esas fortuitas semejanzas entre La Gaviota y el Faus. tc de Del Campo podrían anotarse también entre La Gaviota y el Faust de Pitarra. En cuanto a los dos Faustos, el catalán y el criollo, los he cotejado y no encuentro una sola palabra que indique que Del Campo hubiera leído a Pitarra. De paso: el Faust catalán es inferior al criollo en todo sentido: Pitarra, con su burdo monólogo, destruye la ilusión del espectáculo.

3 Sobre esta "Carta", los hechos que prepararon en Buenos Aires el am. biente propicio para que Del Campo eligiera el tema del Fausto y el proceso de la composición del poema véanse: Angel J. Battistessa, "Génesis periodística del 'Fausto' - una desconocida prefiguración de ese poema 'gauchesco"', Anales del Irstituto Popular de Conferencias, XXVII (1942), 309-321; Justa Lucero, El tema del Fausto en 1866. Buenos Aires, 1963; Rafael Alberto Arrieta, "Estanislao del Campo", Historia de la Literatura Argentina, Buenos Aires, 1959, III, 5.3-118. 
los paisanos van crocando las escenas de la ópera es también espectacular. Los ademanes de los paisanos echados al aire libre se desvían hacia el tabaco, la ginebra, los caballos, el paisaje, pero al hacerlo marcan con énfasis las crisis, fectos teatrales y puntos culminantes de la acción que transcurrió en el recinto cerrado del teatro. Tan espectacular es esa progresión dramática que ya se la ha representado, en una versión cinematográfica (que vi allá por 1930) y en varias versiones teatrales (de las que la última que conozco es la de María Escudero, en 1963). La descripción del poema se despliega y vemos una naturaleza rioplatense que tiene algo de bastidor teatral y un bastidor teatral que tiene algo de naturaleza rioplatonse. Este desdoblamiento interior -relato de un relato o espectáculo dentro de un espectáculo- convenía muy bien a la actitud irónica de Del Campo."

"Recuerdo - le escribió Ricardo Gutiérrez a Del Campo- que una noche alegre en que yo apreciaba infiniclad de ocurrencias criollas que decía usted al vuelo, a propósito de las escenas del Fazsto, lo tenté a escribir en estilo gaucho sus impresiones de ese espectáculo". "Es posible que, en esa noche alegre en que se puso a improvisar la parodia del Fatusto, Estanislao del Campo se sintiera Anastasio el Pollo (después de todo era su seudónimo) y a su amigo Gutiérrez lo convirtiera en una especie de Laguna. Repárese en la deliberada coincidencia de las fechas: el Pollo reseña la ópera a Laguna "cuatro o cinco noches" después de su estreno, que frue el 24 de agosto de 1866; y fue justamente el 29 de agosto cuando Del Campo dedicó el primer manuscrito de Fausto "a mi amigo el pocta Ricardo Gutiérrez". Intencionalmente, pues, la misma situación se reproduce en el arte y en la vida. Y si Del Campo se desdobla en el Pollo y a Gutiérrez lo desdobla en Laguna ino setá porque le cosquillea en el ánimo la traviesa idea de otra doblez sociológica?: los burgueses de Buenos Aires que asistieron al estreno de Fausto en e1 Teatro Colón se creían muy curopeos pero eran tan fronterizos con respecto a París como los gauchos con respecto al Teatro Colón. La ciudad y la campaña se interpenetraban, en hombres y paisajes. Del Campo no era paisano pero - como todos los criollos de Buenos Aires en esos años- llevaba un paisano adentro. Aceró H. Meyer cuando, en una de

4 Sobre el desdoblamiento interior véase mi trabajo "La forma "autor-petsonaje-autor' en una novela mexicana del siglo XVIF", Crítica intema, Madrid, 1961; Leon Livingstone, "Interior duplication and the problem of form in the nodern Spanish novel", PMLA, LXYIII, 4, part 1 (1958); Robert Nelson, The Play within the Play, New Haveil, 1958.

5 Ricardo Gutiérrez, Carta publicada al frente de la edición princeps, Fausto, Buenos Aires, 1866 , p. 10. Gutićrece, que había idealizado al gaucho en "La fibra sálvaje" (1860), lo idealizará aún más en "Lázaro" (1869). 
las dos láminas para el Fausto, dibujó al Pollo con cabeza de Estanislao del Campo.

Como quiera que sea, Del Campo entra y sale de su poema, como un fantasma. A veces se identifica con el Pollo (hasta el punto que lo hace versificar con su musa romántica y culta, como en esa elaboración -versos 1137-1168- del viejo tema de "la rosa efímera"), a veces lo mira objetivamente, desde lejos, con ojillos críticos y burlones, a veces la ironía consiste en auto-caricaturizarse en figura de paisano.

Claro que ni Del Campo ni Ricardo Gutiérrez ni los amigos contemporáneos del poema vieron lo que hoy ve un crítico formalista, que usa filtros coloreados para separar las distintas filigranas del texto. Ellos estaban atentos al "sentimiento", al "fondo", a los valores más visibles en una época romántica. A mí me interesan "formas" que están en el texto aunque ni Del Campo ni Gutiérrez repararan en ellas. Pero así y con todo véase cómo Gutiérrez, en su carta a Del Campo, insiste en que el mérito de Fausto está escondido a los ojos del lector común: hay que tener en cuenta el drama de Goethe, la ópera de Gounod, y comprender que Del Campo, más que ver como paisano, siente como él porque, con "luz interna", iluminó por dentro al Pollo, fue el Pollo, y desde ese avatar se expresó. "El que entra a la seriedad —dice Gutiérrez- ha pasado por la malicia". Más adelante volveremos sobre esta forma humorística: tomar en scrio la ficción increible.

Algunos críticos realistas han dañado el poema al examinarlo como documento y no como obra de arte. Se inmiscuyen en la psicología de los paisanos o en la sociología de las relaciones entre las costumbres del campo y las instituciones de la ciudad. Pero el Pollo y Laguna, el campo y la ciudad no fueron reales para Estanislao del Campo cuando se proyectó idealmente en su poema. Todo el Fausto es absurdo porque su autor es un humorista. Sin duda es imposible que un paisano compre una entrada al Teatro Colón y, al oir una ópera en italiano, pueda comprenderla lo bastante para contar su intriga sin advertir, al mismo tiempo, que se trata de una función artística y no de la vida real. Las convenciones que usa Del Campo son increibles y, por lo tanto, no vale la pena --como han hecho algunos críticos- inventariar sus inverosimilitudes. ${ }^{6}$ El Fausto está desdoblado interiormente porque desdoblada estaba la fantasía de su autor: relato de un relato, espectáculo dentro de un es-

${ }^{6}$ Muchos han defendido a Del Campo de la incomprensión de los críticos realistas. Baste citar a Elías Carpena, "Defensa de Estanislao del Campo y del caballo overo rosado", Boletín de la Academia Argentina de Letras, XXIV, $91-92$ (1959), 73-109. 
pectáculo, un Del Campo-Pollo hablando con un Gutiérez-Laguna sobre un drama-ópera de un Goethe-Gounod representado en un Buenos Aires-frontera.

\section{LA MENTIRA ARTÍSTICA}

Los críticos han festejado ya el cómico quid pro quo del poema. Del Campo - dicen-- observa irónicamente la oscilación entre lo real y lo fantástico, lo gauchesco y lo europeo, lo vital y lo artístico; y con guiños de complicidad se comunica con el público culto para divertirse juntos a costa de Pollo y Laguna. La risa - según esos críticos-- retoza solamente en el ánimo del autor y el lector porque, dentro de la obra, el Pollo y Laguna son dos almas cándidas que muy en serio comulgan con ruedas de molino.

¿Y si no fuera así? ¿Y si el Pollo y Laguna también estuvieran comunicándose en un sutil juego de irónica complicidad? No sería nada raro pues todo el Fausto criollo es una galería de espejos deformantes: hay desdoblamientos y duplicaciones, simetrías y contrastes, entrecruzamientos y paralelos. Es evidente que la conciencia de Del Campo reflexionó sobre sí misma, se miró a sus anchas y, humorísticamente, se expresó en formas complicadísimas que han sido estudiadas con el nombre de "reduplicación del fingimiento". ${ }^{7}$

Así como un actor y un espectador se engañan a medias para participar en la unidad de ilusión del drama, dos amigos - sean Alfa y Betapueden también celebrar un tácito pacto de mutuos engaños para compartir el placer de un cuento fantástico. Veamos los componentes de esta vertiginosa operación psicológico-social.

Alfa, que cuenta con intención humorística, simula un aire de seriedad. Confía en que Beta, dentro del circuito simpático de la conversación, ha de simular que cree en esa simulada seriedad. Pero Beta, a su vez, puede exagerar su simulación de la credulidad. La exagera tanto que la hace increible: ¡la suspensión del juicio, la entrega total de la atención, los signos aprobatorios, los ademanes admirativos son demasiado ingenuos para ser verdaderos! Y si Beta, a fuerza de exagerarla, hace increible su simulación es porque quiere que Alfa esté seguro de que a su simulación de seriedad se ha respondido con una simulación de la credulidad. Con esta irónica espiral ambos amigos consiguen cons-

7 Georges Delacre, "La reduplicación o la conciencia espejada", La Torre, $\mathrm{X}, 37$ (1962), 113-129. Véase también Vladimir Jankélévitch, L'ironie ou la bonne conscience, Paris, 1950. 
truir allá arriba, muy por encima del placer de contar y de oir contar, una alta figura objetiva: si Beta no toma en serio el simulado aire de seriedad de Alfa es porque lo verdaderamente serio es el cuento mismo, por humorístico que sea. Un fingimiento a la primera potencia suscitó un fingimiento a la segunda potencia que a su vez ha suscitado un fingimiento a la tercera potencia; y así el fingimiento se va elevando hacia una mentira, no simple, sino tan compleja como el arte mismo. Es la mentira artística.

No estoy seguro que sea esto lo que ocurre en el Fausto pero aquí va la idea como conjetura. Téngase en cuenta, antes de rechazarla, que mi actitud no es realista: describo una forma interior del Fausto, esto es, una forma mental de su autor, y ya he dicho que este autor suele meterse como un fantasma dentro del cuerpo de su personaje Pollo y dialogar con Laguna como si estuviera dialogando con Gutiérrez o con cualquier otro amigo culto. ${ }^{8}$ Diálogo que, por sus argucias, recuerda el que suele acompañar a ese juego de naipes que se llama, justamente, "truco". Si el Fausto falsea la mentalidad del paisano no es porque Del Campo la ignore, sino porque adrede pone espejos de ciudad en la vida al aire libre. De la mentalidad del paisano lo que eligió para describirlo en su poema fue precisamente ese lado que le permitía identificarse con él: esto es, la fama que le habían dado los románticos de ser una criatura astuta, ingeniosa, imaginativa, que se expresaba económicamente con frases de doble intención. Lo que importa es comprender la estrategia literaria de Del Campo: 1) llama la atención del lector sobre la materia de su poema, que es una plática entre paisanos sobre una ópera; 2) despierta en el lector un doble interés, por esa materia narrativa y por el modo con que se la narra; y 3) convence al lector que la materia, en vez de ser el fin, es sólo el medio para la realización del poema. Ahora el lector, curado de los prejuicios que vienen de la realidad exterior, puede concentrarse en el poema mismo, como pura ficción. $\mathrm{Y}$ ya es hora de que pase a exponer mi conjetura.

8 Del Campo solía sentir que había en él dos "yo" y que uno se le metía en el otro. Describió festivamente esta sensación de "estar dos en uno" a propósito del yo "que se burlaba de todo" y el yo serio en el amor, en "Monólogo de un tronera", Poesía, Buenos Aires, 1870, pp. 111-115; no es la situación cue aquí nos interesa pero valga el esquema psicológico del "¿si es que yo no soy yo quién soy entonces?". Otro ejercicio en transferencia del "yo": en "Batalla de Pavón. Parte del general vencido", ibid., 121, Del Campo, jocosamente, habla en primera persona como si Urquiza fuera quien se dirige al Presidente Derqui. En cuanto a la duplicidad del poeta que versifica lo que no siente, véase "El Album", ibid., 137. 
Laguna y el Pollo son paisanos, no gauchos. ${ }^{9}$ Se han vuelto a encontrar, después de años: "-_Ahijuna! ¿No es el Pollo? - Pollo, no, ese tiempo se pasó". Se abrazan — "sus dos almas en una acaso se misturaron"- y así afinizados se sientan a orillas del río a disfrutar de la amistad ociosa y conservadora. Laguna menciona, casualmente, al diablo. $Y$ entonces el diablo salta del folklore americano a la fantasía del Pollo, se convierte allí en la figura visible de un actor disfrazado de Mefistófeles, mueve la voluntad fabuladora $y$ hace surgir el cuento. El gesto automático de la señal de la cruz con que Laguna reacciona las dos ocasiones en que el Pollo dice haber visto al diablo responde más al oscuro fondo supersticioso formado por las creencias populares que a la clara superficie racional donde se está reflejando, en ese mismo instante, el cuento que se oye. Al cuento van a gozarlo -uno contándolo, el otro oyéndolo- como se gozan las mentiras.

Su conversación - ¿con la boca chica?- comienza, precisamente, con una mentira. Laguna acaba de mandarse la andaluzada de que una vez su caballo esperó durante tres días, y sin moverse, a que su jinete volviera de un desmayo. El Pollo le ve el juego: "¡Bien haiga gaucho embustero! ¿Sabe que no me esperaba que soltase una guayaba de ese tamaño aparcero?". Y después de exagerarle el embuste hasta el absurdo agrega: "¿y se ha figurao que yo ansina nomás las trago?"

Si él Pollo no es un papanatas de grandes tragaderas ¿cómo se tragó eso de que la ópera italiana ocurría de verdad? Quizá no se lo tragó, y de ahí viene el tono de socarronería, con que narra. Cuando Laguna lo incita con un "¡Canejo! ¿Será verdá? ¿Sabe que se me hace cuento?”, el Pollo recurre a la coartada típica de todo mentiroso: "No crea que yo le miento: lo ha visto media ciudá". Cuando Laguna vuelve a dudar: "¿Será cierto?", recurre a esta apoyatura idiomática que, por su énfasis, también pertenece al arsenal del mentiroso: "Mire: que me caiga muerto si no es la pura verdá". ("Me caiga muerto" dice también el mentiroso en "El y Ella", una de las composiciones festivas que Del Campo recogió en sus Poesías).

Tampoco Laguna es tan crédulo como parece. Cuando oye que el diablo engatusó a Fausto, inmediatamente se le ocurre: "¿No era un dotor muy projundo? ¿Cómo se dejó engañar?". Con sus comentarios va hundiendo más el relato en el buen humor: si el Pollo habla del doc-

9 Como "paisanos" los describe Del Campo y también ellos hablan de "paisanos" y "paisanada": sólo en broma se llaman "gaucho" uno a otro (versos 91 y 269). En el título sí apareció 'gaucho', acaso para indicar el género ál que pertenecia: Fausto: Impresiones del gaucbo Anastasio el Pollo en la represe'ntación de esta ópera. 
tor Fausto como de un hombre real, él lo identificará con un real coronel Fausto; si el Pollo cuenta que el diablo rayó con el sable el suelo y salió fuego, él festejará: “¿Qué sable para yesquero!". No es hombre ignorante: al viento que hace volar un sombrero lo llama "céfiro"; al apero de su caballo, "chafalonía" (palabra tan urbanamente descriptiva que arranca al Pollo esta ponderación chacotona: "iEso sí, siempre pintor!"').

Es posible pues, que el Pollo y Laguna estén haciendo la comedia, como en esa escena en que el Pollo dice que al oir los lamentos de la rubia Margarita sintió que se le asomaban dos lágrimas. Laguna se burla con un "iqué vergüenza!". El Pollo se guarda por el momento la pulla y se pone a pintar la triste condición de la mujer desamparada hasta que ahora es Laguna quien dice haberse conmovido: "Vea si no el lagrimón que al oirlo se me ha salido". Esto es lo que se llama "llorar con un ojo". Y entonces el Pollo, triunfante, se toma la revancha y le retruca: "iqué vergüenza!". Esto, en el primer manuscrito, donde la intención del juego fue evidente: el "iqué vergüenza!" de Laguna se repetía como en eco irónico con otro "iqué vergüenza!" del Póllo. En la edición definitiva, por distracción, Del Campo estropeó ese perfecto marco verbal al sustituir el segundo "iqué vergüenza!" por "¡oiganlé!", pero aun así se ve su intención lúdica. ${ }^{10} \mathrm{La}$ sal del poema no viene de esas lágrimas.

No hay duda que Laguna admira al Pollo, ya famoso por su inventiva: "Vean cómo le busca la güelta... ¡ ¡bien haiga el Pollo, siempre larga todo el rollo de su lazo!"; "Vean si es escarbador este Pollo"; "No he visto gaucho más quiebra para retrucar jahijuna!". Por su parte, el Pollo respeta los alcances de la inteligencia de Laguna: "Usté, que es alcanzador", le dice.

Laguna está pendiente de sus palabras y no lo deja distraerse: "le ruego que me dentre a relatar"; "Vaya amigo, larguesé"; "no le permito que me merme ni un chiquito del cuento que ha comenzao"; "Siga su cuento, cuñao"; "Priéndale al cuento que ya no lo vuelvo a atajar yo".

Cuando el Pollo se florea con pasajes de empeño Laguna le reclama que no se desvíe del relato. Después de doce redondillas ("Sabe que es linda la mar?") Laguna lo interrumpe: "¡Ah, Pollo! Ya comenzó a meniar taba; ¿y el caso?". Después de trece redondillas sobre "el verdadero amor" Laguna vuelve a interrumpirlo: "Güeno, amigo: así será, pero me ha sentao [frenado] el cuento". Después de diez redondillas

10 Amado Alonso, "El manuscrito del 'Fausto' de la colección Martiniano Leguizamón", Estudios linguísticos. Temas bispanoamericanos, Madrid, 1953. 
sobre el amanecer, otra vez: "Dice bien, pero su caso se ha hecho medio empacador". Cuando el Pollo dice: "Ya se me quiere cansar el flete de mi relato", Laguna se apresura a animarlo con la misma metáfora hípica: "Priendalé guasca otro rato: recién comienza a sudar".

Sí. Laguna, ante el arte de contar del Pollo, hace la vista gorda y responde con su arte de escuchar; y ambos saben que están haciendo eso, arte, y que el cuento es una mentira artistica. Picardía y manga ancha. Laguna, por el papel pasivo que le toca, es el que parece más candoroso. Pero ¿no será que con sus dudas, aspavientos, preguntas retóricas y asombros fingidos está provocando al Pollo, tirándole de la lengua para que se luzca con lo mejor que tiene?

Al final Laguna paga los gastos del Pollo, en la fonda; que es lo que siempre ha hecho el público con quienes lo entretienen. El Pollo es un juglar.

\section{IMITACIÓN DE LA IMITACIÓN}

Y este juglar es un poco Del Campo mismo. El Fausto fue para él una diversión intelectual, no tanto a costa de los gauchos, sino, usando el medium gauchesco, más bien a costa de la ópcra. La leyenda del doctor Fausto había surgido del pueblo; Goethe la aristocratizó en su drama; Gounod la vulgarizó en su ópera. A primera vista Del Campo pareció cerrar el círculo restituyendo al pueblo la popular leyenda medieval, pero en realidad lo que hizo fue imitar burlescamente la imitación operística de Gounod.

El Fausto de Goethe aspiraba a valores superiores: la vitalidad, el amor, el episodio de Margarita eran sólo anécdotas del titánico afán humano de trascender sus propias limitaciones. A ese doctor Fausto lo disminuyó Gounod. Ya el no haber tenido en cuenta la segunda parte del drama de Goethe fue un modo de disminuir a su héroe. Desesperado porque sus estudios no le han dado ni conocimiento ni fe, el Fausto de Gounod pide a Mefistófeles, no riqueza ni gloria ni poder, sino juventud, placer y amor. Al filósofo se le abre un sensual apetito. Mefistófeles le muestra entonces, y sólo entonces, la imagen de Margarita, de la que Fausto inmediatamente se enamora. Del Campo reduce aún más el papel del doctor Fausto. Al alzarse el telón el Pollo ve a un Fausto que ya está enamorado de Margarita: "Dijo que nadá podía con la ciencia que estudió; que él a una rubia quería pero que a él la rubia no". Este Fausto es un hombre cualquiera enamorado de una mujer cualquiera: hasta Mefistófeles es un alcahuete cualquiera. El relato altera 
d orden de las escenas porque en Del Campo ha habido un cambio en la intención: su Fausto, con el corazón todavía joven, pacta con el diablo para conseguir una mujer deseada. Gounod, sacrificando el signif́icado filosófico del drama de Goethe, se había limitado al episodio de Margarita; al que se permitió agregar el personaje Siebel; Del Campo se ceñitá aún más a lo sentimental, ridiculizará como superfluo al gaián Siebel (que para peor canta con voz de soprano) y se mofará de la ópera misma. Para un lector de Goethe - y a Goethe no sólo se lo leía en la Argentina, sino que Esteban Echeverría había traducido y elaborado escenas de su Fausto- la ópera de Gounod, de excesiva pantomima y cantada en italiano, debía de parecer una copia rebajadora. (Carlos Guido y Spano, en su carta a Del Campo, se refiere a "la mano impía del compositor" Gounod). Del Campo decidió copiarla aún más rebajadamente. Para ello no sólo asistió al estreno, sino que también leyó el libreto, sea en la traducción italiana de Achille de Lauzières o en la traducción de esa traducción que se publicó entonces en Buenos Aires. ${ }^{11}$ No hay que descartar la posibilidad de que él mismo interviniera en esa traducción. Que leyó el libreto, no hay duda. Los detalles descriptivos revelan recuerdos visuales del vestuario, el decorado, las tramoyas y los movimientos escénicos de la función; pero los detalles narrativos que, en buen orden, anudan los hilos de la trama - más los cortes de peripecias y partiquinos que no le servían-, revelan un conocimiento crítico del libreto.

Se va a la ópera para oir música, que es lo esencial: el libreto es lo de menos, y nadie se queja si no entiende las palabras. Los actores son cantantes que subordinan la acción a la melodía. Una ópera, vista por un sordo, es un espectáculo grotesco. Pues bien: Del Campo-Pollo narra como si no hubiera oido más música que la del introductorio adagio molto y el baile, y no alude ni una sola vez al canto. En cambio elige del

11 El Fausto de Charles F. Gounod se estrenó en París en 1859 con Libreto de Jules Barbier y Michel Carré. Lo tradujo al italiano Achilie de Lauzières y en 1863 se publicó en folleło: Faust, dramma lirico in cinque atti... da rappresentarsi nel Regio Teatro alla Scala la Quaresima del 1863, Milano, 1863. La traducción del libreto italiano se publicó, anónima, simultáneamente en El $\mathrm{Nat}$ cional y La Nación Argentina (agosto de 1866) y en un folleto: Fatusto, Buenos Aires, Empresa de Don Antonio Pestalardo, 1866. En su primera versión -la que conoció Del Campo- fue una "opéra comique", o sea, una ópera en la que támbién había diálogos hablados, no cantados; desde 1869 las partes habladas fueron reemplazadas por música, y así es como la he oído. Sobre la diferencia entre Goethe y Gounod véase Ernst Newman, "Faust in music", Musical Studies, London, 1905, pp. 71-77: "risible monstruosidad", "perpetrada por Gounod y sus cómplices", "barata vulgarización de Goethe con una mezcla de pantomima, noveleta y tarjeta navideña", "débil y ridícula" cuando la comparamos con el drama, dice Newman. 
texto los pasajes más susceptibles al ridículo, como ése en que "el diablo comenzó a alegar gastos de viaje". Al necesario movimiento de los cantantes durante la representación -unos que hacen mutis porque ya han cantado, otros que se quedan o entran porque les toca cantar- lo explica con una lógica menoscabadora: el diablo se lleva a la vieja Marta para mostrarle un chancho y la larga "jediendo entre algún maizal"; el capitán Valentino vuelve de la guerra del Paraguay porque le han concedido un día "en comisión" para visitar la ciudad; la rubia Margarita "en un banco se sentó, un par de medias sacó y las comenzó a zurcir" y después "dentró a espulgar un rosal por la hormiga consumido". Del Campo suprime algunos móviles serios de la acción dramática para reirse más a gusto. Por ejemplo. En la ópera (II, ii) Mefistófeles coge las manos de Wagner y Siebel y lee en ellas sus destinos. No sólo Del Campo elimina a Wagner, sino que hace que Mefistófeles "registre los dedos" de Valentino, cosa que en la ópera no ocurría. Ahora bien: la mano de Siebel, en la que Mefistófeles practicó su quiromancia, quedó maldita y por eso, en la escena del jardín, marchita las flores que toca. Sólo después de bañarla en agua bendita recobrará su pureza y podrá juntar el ramo que of rece a su amada. El Pollo, por saltarse esas teologías y demonologías, permite el chiste de que Siebel (Don Silverio) se arma un ramo en el jardín de Margarita para "osequiarla... con las mesmas flores de ella". Las modificaciones que el relato introduce en la acción de la ópera tienden, pues, a ridiculizarla. La única excepción proviene de la romántica simpatía con que el Pollo habla de Margarita: en la ópera Valentino, antes de morir, maldice a su hermana; el Pollo -compadecido- calla ese detalle y dice que los dos hermanos "a gatas medio alcanzaron a darse una despedida". En la compasión por Margarita, además del romanticismo, entraban los sentimientos de Del Campo, sentimientos cristianos y también los sentimientos amorosos que expresó en sus poesías a "Lucila", pero nada de esto alcanzó a solemnizar el poema, cuya tónica dominante es la humorística. ${ }^{12}$

12 En "A unas lágrimas derramadas durante la representación de La Travia$t d^{\prime}$, Poesias, p. 73 - con esta ópera se había inaugurado el Teatro Colón en 1857-, la actitud de Del Campo no es humorística: pide a su amada - i"Lucila"? - que "ya que hay tanta ternura / en el vaso de tu alma/que hasta un dolor fingido / hace que viertas lágrimas", llore también por él, amante infortunado. Compárense las dos lágrimas que asomaron a los ojos de la mujer, ante el dolor fingido de La Traviata, con las dos lágrimas que asoman a los ojos dẹl Pollo ante el Fausto, 


\section{Contrapunto de estilos}

Del Campo había versificado en unas ocasiones como poeta urbano y en otras como poeta gauchesco. Ahora, en el Fausto, decidió entrecruzar ambos estilos. Se puso a tocar la guitarra con técnica de lira y la lira con técnica de guitarra confiado en que tales préstamos recíprocos favorccerían la expresión poética. No ofreceré una antología de sus aciertos en ese lírico guitarreo. Prefiero llamar la atención sobre un pasaje desde donde podemos espiar al poeta en su estudio, armonizando lo personal y lo popular.

Que el gaucho metaforizara con imágenes hípicas era normal. En nuestro Fausto hay varias metáforas así: la popa-anca, el cuento-flete... La que ahota me interesa es ésa en que el Pollo compara "el cielo con un pingo" para decir que, en la madrugada, "estaba mudando pelo". Laguna, con fuerte conciencia social, rechaza lo que para él era una inaudita demasía individual: "No sea bárbaro, canejo! ¡Qué comparancia tan fiera!" Y entonces Del Campo, para explicar cómo se puede crear verbalmente elaborando las experiencias comunes de la gente de a cabaIlo - gente ducha en reconocer los colores del pelaje- hace que el Pollo defienda su innovación: "No hay tal: pues de zaino que era se iba poniendo azulejo". Aunque con perspectiva interior de gaucho, la metáfora del cielo-caballo fue original de Del Campo. Contrapunto entre la tradición y la invención.

Juan Carlos Gómez le había aconsejado, por carta, que arrojara la guitarra del gaucho; Del Campo le contestó que había que salvar, antes que el progreso y la industrialización urbana los destruyeran, los "giros especiales y la peculiar fraseología del lenguaje de nuestros pobres gauchos, picaresco unas veces, sentido otras, y pintoresco siempre" (Poesias). Pero lo que hizo en su Fausto fue, no conservar una "lengua", sino usar un "habla" con tal energía personal que la convirtió en chispeante "estilo".

He hablado de cinco formas: inversión, desdoblamiento, reduplicación, imitación, contrapunto. Todas, formas de una polaridad espiritual, la de la ironía. De aquí el juego de perspectivas que hace del Fausto el poema más complejo de toda la literatura gauchesca. 
